\title{
MicroRNA-3651 promotes colorectal cancer cell proliferation through directly repressing T-box transcription factor 1
}

\author{
CHANGFENG LI ${ }^{1}$, DAYONG DING ${ }^{2}$, YONGJIAN GAO ${ }^{2}$ and YONGCHAO LI ${ }^{2}$ \\ Departments of ${ }^{1}$ Endoscopy Center and ${ }^{2}$ Gastrointestinal Colorectal Surgery, \\ China-Japan Union Hospital of Jilin University, Changchun, Jilin 130033, P.R. China
}

Received July 13, 2019; Accepted November 15, 2019

DOI: $10.3892 / \mathrm{ijmm} .2020 .4458$

\begin{abstract}
Colorectal cancer is a commonly diagnosed gastrointestinal malignancy worldwide with a high mortality rate. Accumulating evidence has indicated that the expression of a number of microRNAs (miRNAs) is associated with the development of colorectal cancer. However, the precise molecular mechanism of these miRNAs in regulating cancer progression is yet to be determined. In the present study, miR-3651 was demonstrated to be overexpressed in colorectal cancer tissues compared with normal tissues, and to be associated with the tumor-node-metastasis stage. The downregulation of miR-3651 was found to induce growth arrest and apoptosis in colorectal cancer cells. In addition, western blot analysis demonstrated that the downregulation of miR-3651 inactivated PI3K/AKT and MAPK/ERK signaling in colorectal cancer cells. Bioinformatics analysis predicted T-box transcription factor 1 (TBX1) as a potential target gene of miR-3651, and a dual-luciferase reporter assay confirmed that TBX1 was directly repressed by $\mathrm{miR}-3651$. The results of the current study also indicated that TBX1 was associated with the miR-3651 mediated activation of oncogenic signaling and colorectal cancer cell proliferation. In conclusion, the results of the current study revealed the oncogenic potential of miR-3651 in colorectal cancer.
\end{abstract}

\section{Introduction}

It is estimated that 1.8 million new colorectal cancer cases and 881,000 colorectal cancer-associated mortalities occurred worldwide in 2018 (1). Colorectal cancer is responsible for $\sim 10 \%$ of mortalities associated with cancer and exhibits the second highest cancer mortality rate worldwide (1). Conventional surgery, chemotherapy and radiotherapy are

Correspondence to: Dr Dayong Ding, Department of Gastrointestinal Colorectal Surgery, China-Japan Union Hospital of Jilin University, 126 Xiantai Road, Changchun, Jilin 130033, P.R. China

E-mail: dingdayongdoc@aliyun.com

Key words: microRNA-3651, T-box transcription factor 1, colorectal cancer commonly used for the treatment of patients with colorectal cancer (2). Recently, targeted therapy against vascular endothelial growth factor and epidermal growth factor receptor in combination with chemotherapy has been demonstrated to prolong the overall survival of patients (3). The identification of novel oncogenes and tumor suppressors may aid in the investigation and development of new agents to improve the prognosis of patients with colorectal cancer in the future.

MicroRNAs (miRNAs) are characterized as small (18-25 nucleotides), single-stranded non-coding RNA molecules. In recent years, accumulating evidence has demonstrated that miRNAs are important regulators of the majority of physiological processes in mammal cells (4). The seed region of miRNAs can form a complementary base pair with the 3'-untranslated region (3'UTR) of target gene mRNAs, leading to mRNA degradation or translation inhibition (5). The dysregulation of miRNAs has been reported to be associated with the initiation and development of a number of cancer types (6). In colorectal cancer, a number of miRNAs, including miR-17-5p and miR-21, have been revealed to be key drivers of tumorigenesis (7,8). Furthermore, miR-1290 and miR-139-3p are markedly decreased and increased in colorectal tumors, respectively, and can serve as biomarkers for patients with colorectal cancer $(9,10)$. Although numerous differentially expressed miRNAs have been identified via RNA sequencing and microarray $(11,12)$, the roles and function of the majority of these molecules have not yet been determined. Through the retrieval and analysis of previously published microarray data (11), miR-3651 has been identified to be significantly upregulated in colon tumors (11). The prognostic value of miR-3651 has previously been evaluated in esophageal squamous cell and oral squamous cell carcinomas $(13,14)$. However, the role and molecular mechanism of this miRNA remain unclear in colorectal cancer.

T-box transcription factor 1 (TBX1) is known to be a developmentally important transcription factor, which has a 180-200 amino acid conserved DNA-binding domain, namely the T-box (15). The expression of TBX1 is essential for the proliferation and differentiation of heart progenitor cells, and is important for the development of the heart, inner ear, sweat gland, teeth and thyroid (16-19). TBX1 has also been identified as a novel tumor suppressor in thyroid cancer and basal cell carcinoma $(20,21)$. As a transcription factor, TBX1 interacts with chromatin remodeling complexes to control the expression 
of numerous genes (22). TBX1 has also been reported to control the activity of phosphoinositide-3 kinase/protein kinase $\mathrm{B}$ (PI3K/AKT) and mitogen-activated protein kinase/extracellular signal-regulated kinase (MAPK/ERK) signaling in thyroid cancer cells (20). The downregulation of TBX1 in tumor cells is due to promoter methylation and aberrant miRNA expression $(20,21)$.

In the present study, a published miRNA expression profile of colon tumors and normal tissues was analyzed, in combination with reverse transcription-quantitative polymerase chain reaction (RT-qPCR) examination of collected specimens. It was observed that miR-3651 was significantly upregulated in the colon tumor tissues compared with the normal tissues. In vitro assays further revealed that downregulation of miR-3651 inhibited the proliferation and induced the apoptosis of colorectal cancer cells. Furthermore, it was demonstrated that miR-3651 targeted TBX1 to control the PI3K/AKT and MAPK/ERK signaling pathways. Collectively, the data of the current study demonstrated the clinical relevance of miR-3651 in colorectal carcinogenesis.

\section{Materials and methods}

Sample collection. Normal and tumor tissues were collected from 40 patients who underwent surgery at the China-Japan Union Hospital of Jilin University (Changchun, China) between July 2016 and January 2018. The patient characteristics were recorded following enrollment and included the following: Age, sex, tumor size, degree of tumor differentiation and tumor-node-metastasis (TNM) stage (23). No patients received chemotherapy or radiotherapy prior to surgery. The experiments were performed under the supervision of the Ethics Committee of the China-Japan Union Hospital of Jilin University. Written informed consent was acquired from all participants. Tissues were immediately stored in liquid nitrogen prior to subjecting to RNA extraction.

Cell culture and transfection. A normal colonic mucosal cell line (FHC) and two human colorectal cancer cell lines (HCT116 and HT29) were purchased from the American Type Culture Collection and used within 6 months of receipt. The cells were cultured in Dulbecco's modified Eagle medium (Invitrogen; Thermo Fisher Scientific, Inc.) supplemented with $10 \%$ fetal bovine serum (Gibco; Thermo Fisher Scientific, Inc.). Cell culture was performed in a humidified incubator with $5 \% \mathrm{CO}_{2}$ at $37^{\circ} \mathrm{C}$. miR-3651 mimic (5'-AUGGCACUGGUAGAAUUC ACUG-3'), miR-negative control (NC) mimic (5'-CAGUAC UUUUGUGUAGUACAA-3'), miR-3651 inhibitor (5'-CAG UGAAUUCUACCAGUGCCAU-3') and miR-NC inhibitor (5'-UUCUCCGAACGUGUCACGU-3') were synthesized and purchased from Suzhou GenePharma Co., Ltd. The mimics and inhibitors $(50 \mathrm{nM})$ were transfected into HCT116 and HT29 ells using Lipofectamine ${ }^{\circledR} 3000$ (Invitrogen; Thermo Fisher Scientific, Inc.), according to the manufacturer's protocol. TBX1 siRNA (5'-UAUUUCUCGCUAUCUUUGCGU-3') and control siRNA (5'-UUCUCCGAACGUGUCACGU-3') were products of Shanghai GenePharma Co., Ltd. siRNAs (25 nM) were transfected into $1 \times 10^{5}$ cells in each well of 24-well plates with Lipofectamine RNAiMax (Invitrogen; Thermo Fisher Scientific, Inc.) following the manufacturer's protocol. A total of 2 days after transfection, the transfection efficiency was determined by reverse transcription-quantitative PCR (RT-qPCR).

Bioinformatics analysis. The data of GSE115513 (11) (containing miRNA expression data of 381 normal colonic mucosa, 51 colon adenoma and 411 colorectal carcinoma) were downloaded from the Gene Expression Omnibus (GEO) database (https://www.ncbi.nlm.nih.gov/geoprofiles/). The data were subsequently analyzed with GEO2R, which was provided by the GEO database. The potential target genes of miR-3651 were predicted with TargetScan software v.7.2 (http://www.targetscan.org/vert_72/).

$R N A$ isolation and RT-qPCR. Total RNA was isolated from the cells and tissues using an RNeasy Mini kit (Qiagen $\mathrm{GmbH}$ ), according to the manufacturer's protocol. The concentration of RNA was then measured using a NanoDrop 2000 system (Thermo Fisher Scientific, Inc.). Next, RNA was reverse transcribed into first-stranded cDNA using a PrimeScript ${ }^{\mathrm{TM}}$ RT reagent kit (Takara Bio, Inc.). Subsequently, the qPCR reaction was performed using TB Green ${ }^{\circledR}$ Fast qPCR Mix (Takara Bio, Inc.) on a CFX-96 Realtime system (Bio-Rad Laboratories, Inc.). The qPCR conditions included two steps: Step 1: $95^{\circ} \mathrm{C}$ for $30 \mathrm{sec}$; and step 2: 35 cycles of $95^{\circ} \mathrm{C}$ for $15 \mathrm{sec}$ and $60^{\circ} \mathrm{C}$ for $10 \mathrm{sec}$. GAPDH and U6 served as the internal controls for mRNA and miRNA detection, respectively. The relative gene expression was calculated using the $2^{-\Delta \Delta \mathrm{Cq}}$ method (24). The primer sequences used in qPCR were as follows: Stem-loop primer, 5'-CTCAACTGGTGTCGTGGAGTCGGCAATTCA GTTGAGTCATGTAC-3'; miR-3651 forward, 5'-GCCGAG CATAGCCCGGTCGC-3', and reverse, 5'-CTCAACTGGTGT CGTGGA-3'; U6 forward, 5'-CTCGCTTCGGCAGCACA-3', and reverse, 5'-AACGCTTCACGAATTTGCGT-3'; TBX1 forward, 5'-ACGACAACGGCCACATTATTC-3', and reverse, 5'-CCTCGGCATATTTCTCGCTATCT-3'; GAPDH forward, 5'-ACAACTTTGGTATCGTGGAAGG-3', and reverse, 5'-GCCATCACGCCACAGTTTC-3'.

Protein extraction and western blot analysis. Protein lysates were prepared using a RIPA lysis buffer, and the concentration of lysates was calculated using a BCA Protein Assay kit (both from Thermo Fisher Scientific, Inc.). A total of $20 \mu \mathrm{g}$ protein was then loaded onto an $8 \%$ SDS-PAGE gel and separated using electrophoresis. Proteins were then transferred to a PVDF membrane and blocked with $5 \%$ non-fat milk at room temperature for $1 \mathrm{~h}$. Subsequently, the membrane was incubated in a solution containing primary antibodies at room temperature for $1 \mathrm{~h}$, followed by incubation with secondary antibodies at room temperature for $1 \mathrm{~h}$. The primary antibodies used in western blot analysis were as follows: p-AKT (cat. no. 4060; 1:2,000), AKT (cat. no. 4685; 1:2,000), p-ERK1/2 (cat. no. 4370; 1:2,000) and ERK1/2 (cat. no. 4695; 1:2,000) purchased from Cell Signaling Technology, Inc.; TBX1 antibody (cat. no. ab109313; 1:500) obtained from Abcam; GAPDH (cat. no. AMAB91152; 1:10,000) from Sigma-Aldrich (Merck $\mathrm{KGaA}$ ); and B-cell lymphoma 2 (Bcl2; cat. no. sc-130307; 1:200) Bcl2-associated X protein (Bax; cat. no. sc-7480; 1:200) antibodies from Santa Cruz Biotechnology, Inc. Mouse (cat. no. ab97040; 1:10,000) and rabbit (cat. no. ab7090; 1:10,000) 
A

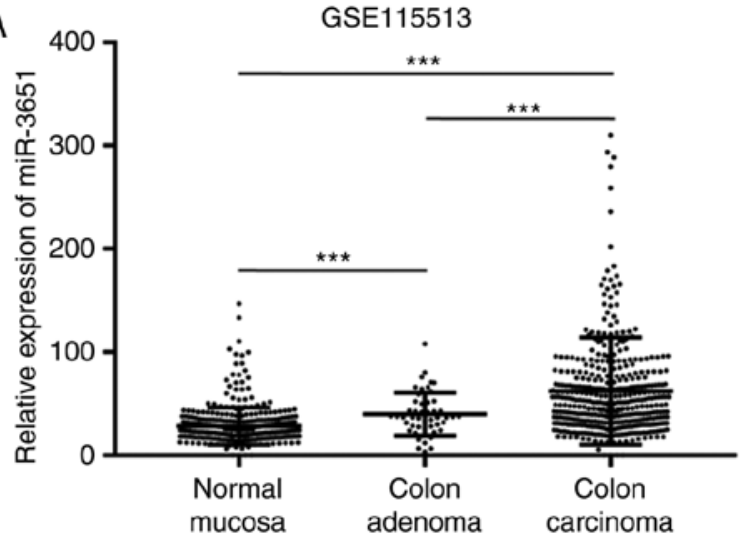

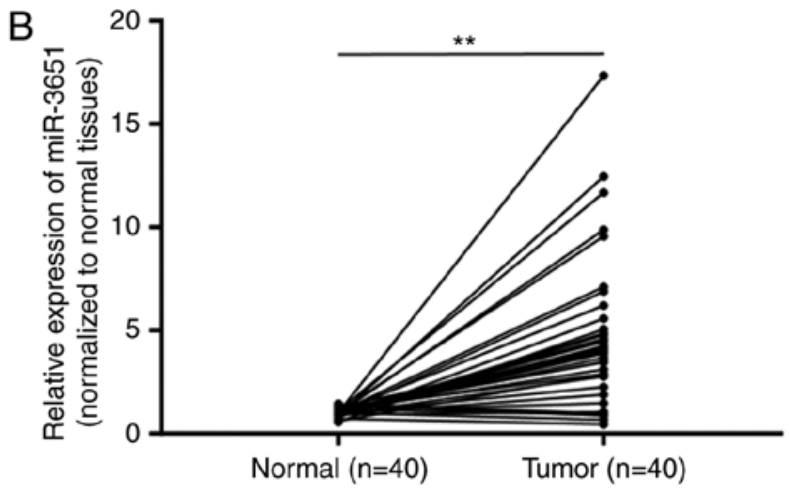

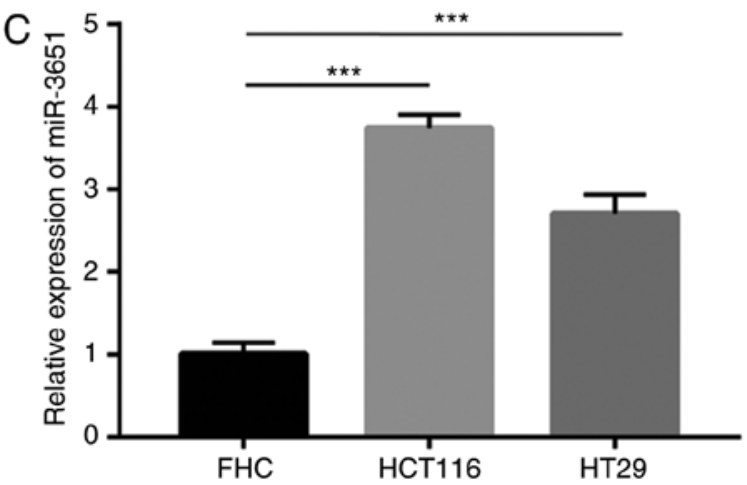

Figure 1. Overexpression of miR-3651 in colorectal cancer. (A) Data retrieved from the Gene Expression Omnibus dataset GSE115513 indicated that miR-3651 expression was elevated in colon adenoma $(n=51)$ and colorectal carcinoma $(n=411)$ tissues compared with the normal colonic mucosa $(n=381)$. $(B) R T-q P C R$ analysis of miR-3651 expression in 40 pairs of tumor and normal tissues from patients with colorectal cancer indicated significantly increased levels in the tumor tissues. The expression of miR-3651 in tumors was normalized to that in the paired normal tissues, with the dotted line indicating the relative expression of miR-3651 in normal tissues. (C) RT-qPCR revealed that miR-3651 was increased in colorectal cancer cell lines (HCT116 and HT29) compared with the immortalized normal colon cells (FHC). ${ }^{* *} \mathrm{P}<0.01,{ }^{* * *} \mathrm{P}<0.001$. miR, microRNA; RT-qPCR, reverse transcription-quantitative polymerase chain reaction.

IgG secondary antibodies were purchased from Abcam. The blots were developed using a Pierce ${ }^{\mathrm{TM}}$ ECL Western Blotting Substrate (Thermo Fisher Scientific, Inc.). ImageJ V.1.6.0 (National Institutes of Health) was used to quantify the protein expression of all blots.

Cell proliferation assay. The cell proliferation ability was detected by Cell Counting Kit-8 (CCK-8) assay (Dojindo Molecular Technologies, Inc., Kumamoto, Japan). Briefly, a total of 10,000 HCT116 or HT29 cells were seeded into each well of 96-well plates. On the following day, cells were transfected with miR-3651 inhibitor or miR-NC inhibitor, and maintained for 3 days. At 0,1, 2 and 3 days after transfection, $10 \mu \mathrm{l} \mathrm{CCK}-8$ solution was added into each well and sustained for a further $2 \mathrm{~h}$. The medium was then transferred to a new 96-well plate, and the absorbance at $450 \mathrm{nM}$ was detected to reflect the cell number.

Cell apoptosis assay. The cell apoptosis rate was determined using a Dead Cell Apoptosis kit with Annexin-V Alexa Fluor $^{\mathrm{TM}} 488$ and propidium iodide (PI; Invitrogen; Thermo Fisher Scientific, Inc.). Briefly, cells were transfected for $48 \mathrm{~h}$, and then harvested and suspended in $1 \mathrm{X}$ Annexin-binding buffer. Next, PI and Annexin V were added into the cell suspension and incubated for $15 \mathrm{~min}$ at room temperature. Following incubation, $400 \mu \mathrm{l} 1 \mathrm{X}$ Annexin-binding buffer was added and mixed. The samples were immediately subjected to flow cytometry analysis. A positive PI and Annexin V result indicated that cells were at the late apoptosis stage, while a negative PI and positive Annexin V result indicated cells at the early apoptosis stage.

Dual-luciferase reporter assay. The TBX1 3'UTR was amplified from HCT116 cDNA and ligated into a pGL3-basic plasmid. Mutations were introduced into the TBX1 3'UTR using a QuikChange Site-Directed Mutagenesis kit (Agilent Technologies, Inc., Santa Clara, CA, USA). In order to perform dual-luciferase reporter assay, $2 \times 10^{5}$ HCT116 or HT29 cells/well were seeded into 24 -well plates, and transfected with miR-3651 mimic or miR-NC mimic in combination with pGL3-TBX1 3'UTR-wild-type (WT) or 3'UTR-mutant (Mut). After $48 \mathrm{~h}$, the relative luciferase activity of each group was detected using a Dual-Luciferase Reporter system (Promega Corporation, Madison, WI, USA) on a Synergy H1 microplate reader (BioTek Instruments, Inc.; Agilent Technologies, Inc).

Statistical analysis. The data were analyzed with GraphPad Prism version 6.0 (GraphPad Software, San Diego, CA, USA), and are presented as the mean \pm standard deviation. Comparisons between two groups were performed by Student's t-test. Comparison between three groups were performed using one-way analysis of variance, followed 
by Newman-Keuls post hoc test. The correlation between miRNA and mRNA expression was analyzed using Pearson correlation analysis. All experiments were performed at least three times. $\mathrm{P}<0.05$ was considered to indicate a statistically significant difference.

\section{Results}

Overexpression of miR-3651 in colorectal cancer tissues and cells. In order to identify the potential oncogenic miRNAs in colorectal cancer, microarray data on the expression of miRNAs in 381 normal colonic mucosa, 51 colon adenoma and 411 colorectal carcinoma samples were collected from the Gene Expression Omnibus database (series GSE115513). miRNAs that were differentially expressed between colon adenoma and normal mucosa were screened. The expression of these miRNAs in colorectal carcinoma and adenoma was subsequently compared. According to the results of this screening strategy, miR-3651 was revealed to be significantly overexpressed in colon adenoma and colorectal carcinoma compared with the normal colonic mucosa (Fig. 1A).

For validation of the elevation of miR-3651 observed in the microarray data, 40 pairs of normal and tumor tissues were collected from patients with colorectal cancer. Using RT-qPCR, miR-3651 expression was detected in the paired tissues and normalized to the normal tissue expression. Consistent with the published microarray data, the miR-3651 levels were found to be increased in $85 \%$ (34/40) of patients (Fig. 1B). The association between miR-3651 expression and the clinicopathological features of patients was further analyzed (Table I). It was observed that high miR-3651 expression was significantly associated with high TNM stage in patients with colorectal cancer (Table I). In addition, miR-3651 expression was subsequently detected in the immortalized colon normal cells (FHC) and two colorectal cancer cell lines (HCT116 and HT29). The results indicated that miR-3651 was increased by 3-fold in HCT116 and HT29 cancer cells as compared with that in normal FHC cells (Fig. 1C).

Downregulation of miR-3651 inhibits colorectal cancer cell proliferation via induction of cell apoptosis. The current study then further assessed the potential role of miR-3651 in colorectal cancer cells. A miR-3651 inhibitor or miR-NC inhibitor was transfected into colorectal cancer cells, and the cell proliferation was detected. Transfection with miR-3651 inhibitor induced an approximately 5-fold decrease in miR-3651 expression in HCT116 and HT29 cells (Fig. 2A). In the cell proliferation assay, the downregulation of miR-3651 significantly repressed cell proliferation during the first 2 days of culture, with a significant reduction in proliferation observed on day 3 in HCT116 cells (Fig. 2B). Similarly, the downregulation of miR-3651 inhibited cell proliferation in HT29 cells (Fig. 2C). To examine whether the cell growth arrest was associated with cell apoptosis, flow cytometry was used to detect cell apoptosis rate in colorectal cancer cells treated with miR-3651 inhibitor. The downregulation of miR-3651 induced significant apoptosis in HCT116 cells (Fig. 2D), with similar results also observed in HT29 cells (Fig. 2E). These data indicated that miR-3651 inhibition reduced colorectal cancer cell proliferation and promoted cell apoptosis.
Table I. Association between miR-3651 expression and the clinicopathological features of patients with colorectal cancer.

\begin{tabular}{|c|c|c|c|}
\hline \multirow[b]{2}{*}{ Clinicopathological feature } & \multicolumn{2}{|c|}{$\begin{array}{c}\text { miR-3651 } \\
\text { expression (n) }\end{array}$} & \multirow[b]{2}{*}{ P-value } \\
\hline & High & Low & \\
\hline Age & & & 0.99 \\
\hline$\geq 60$ years & 11 & 12 & \\
\hline$<60$ years & 9 & 8 & \\
\hline Sex & & & 0.69 \\
\hline Male & 15 & 17 & \\
\hline Female & 5 & 3 & \\
\hline TNM stage & & & $<0.05$ \\
\hline I & 1 & 4 & \\
\hline II & 1 & 5 & \\
\hline III-IV & 18 & 11 & \\
\hline Tumor size & & & 0.48 \\
\hline$\geq 15 \mathrm{~cm}$ & 7 & 4 & \\
\hline$<15 \mathrm{~cm}$ & 13 & 16 & \\
\hline Differentiation & & & 0.99 \\
\hline Poor & 5 & 4 & \\
\hline High & 15 & 16 & \\
\hline
\end{tabular}

miR, microRNA; TNM, tumor-node-metastasis.

Downregulation of miR-3651 deactivates PI3K/AKT and $M A P K / E R K$ signaling in colorectal cancer cells. The $\mathrm{PI} 3 \mathrm{~K} / \mathrm{AKT}$ and MAPK/ERK signaling pathways have been reported to be involved in colorectal cancer cell proliferation and survival (20). The results of western blot analysis demonstrated that the downregulation of miR-3651 significantly decreased the ratio of p-AKT/total (T)-AKT and p-ERK1/2/ T-ERK1/2, but did not alter the expression levels of T-AKT and T-ERK1/2 in HCT116 cells, indicating the deactivation of PI3K/AKT and MAPK/ERK signaling (Fig. 3A and B). A similar effect of miR-3651 downregulation on the ratio of p-AKT/T-AKT and p-ERK1/2/T-ERK1/2 was also observed in HT29 cells (Fig. 3C and D). Since the PI3K/AKT and MAPK/ERK pathways regulate cell apoptosis by controlling the expression of pro-apoptotic and anti-apoptotic proteins in cells $(25,26)$, the levels of such proteins were subsequently investigated in the current study. The results revealed that the expression of the anti-apoptotic protein $\mathrm{Bcl} 2$ was significantly decreased, whereas the expression of the pro-apoptotic protein Bax was significantly increased in HCT116 and HT29 cells transfected with miR-3651 inhibitor (Fig. 3E and F). Taken together, these results indicated that miR-3651 may be associated with mediating the PI3K/AKT and MAPK/ERK pathways to sustain colorectal cancer cell growth.

miR-3651 directly represses TBX1 expression in colorectal cancer cells. miRNAs function through binding to the 3'UTR of target gene mRNAs to inhibit the target gene expression (5). In the present study, the online tool TargetScan was used to 

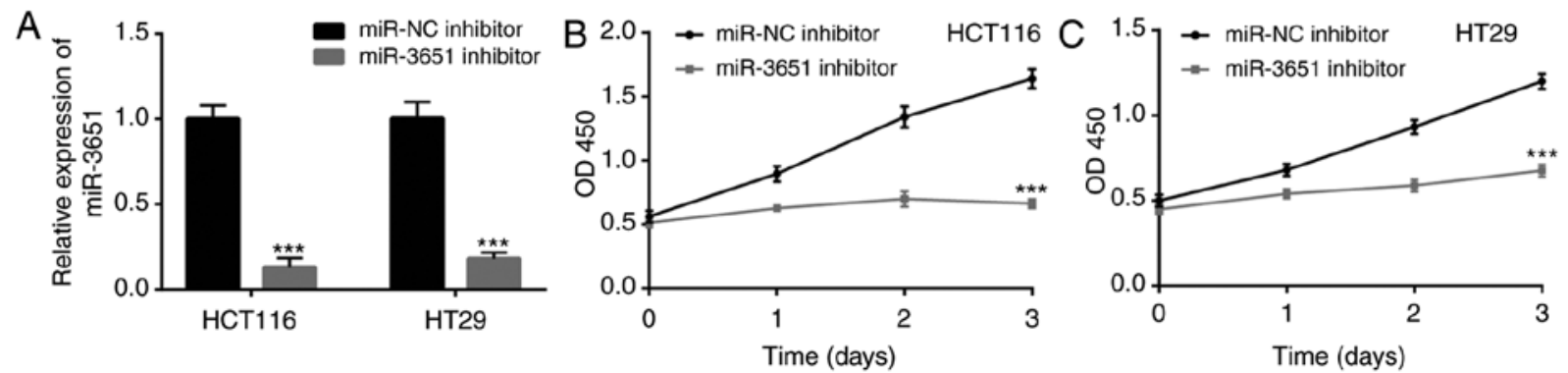

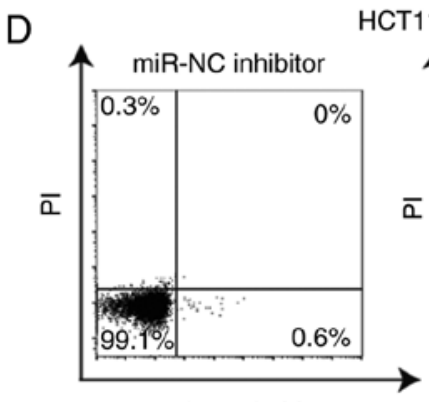

Annexin V

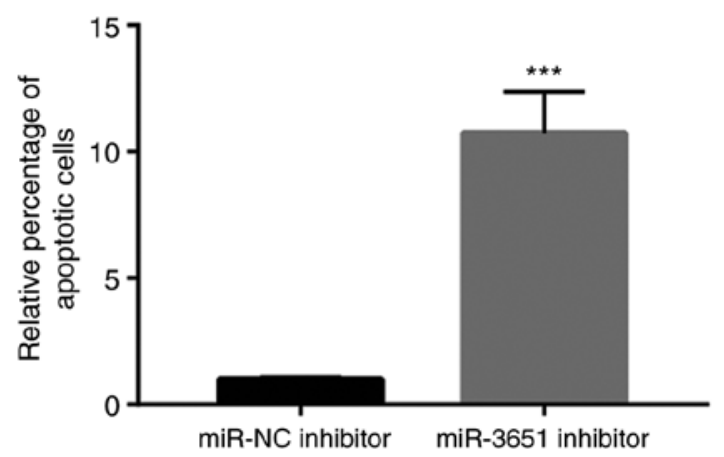

E

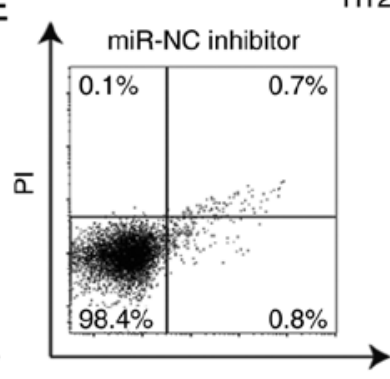

Annexin V

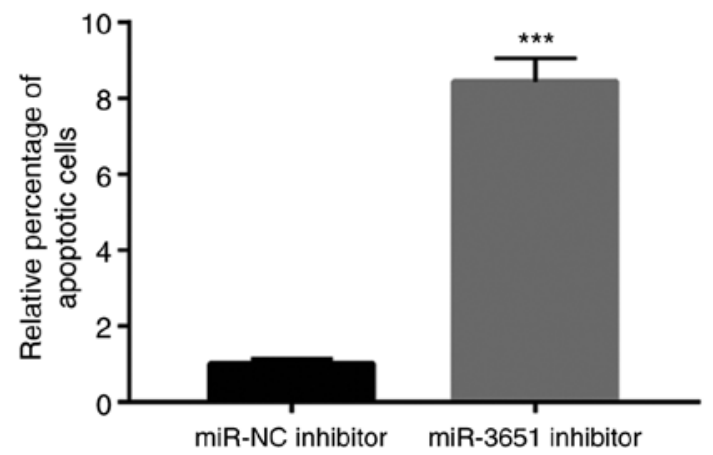

Figure 2. Downregulation of miR-3651 inhibited the proliferation and induced the apoptosis of colorectal cancer cells. (A) Reverse transcription-quantitative polymerase chain reaction revealed that transfection with miR-3651 inhibitor decreased miR-3651 expression in HCT116 and HT29 cells. Cell Counting Kit- 8 assay indicated that downregulation of miR-3651 suppressed the proliferation of (B) HCT116 and (C) HT29 cells. Flow cytometry analysis revealed that miR-3651 downregulation increased the apoptosis rate in (D) HCT116 and (E) HT29 cells. ${ }^{* * *} \mathrm{P}<0.001$ vs. miR-NC inhibitor. miR, microRNA; NC, negative control.

predict potential target genes of miR-3651. Through a literature review, TBX1 was identified as a tumor suppressor in colorectal cancer among the predicted target genes of miR-3651, and the 3'UTR of TBX1 was observed to complementary bind to miR-3651 (Fig. 4A). To explore whether miR-3651 directly regulates TBX1 expression, miR-3651 mimic was transfected in HCT116 and HT29 cells to upregulate miR-3651 expression (Fig. 4B). The dual-luciferase reporter assay indicated that the overexpression of miR-3651 significantly decreased the relative luciferase activity in HCT116 cells co-transfected with TBX1 3'UTR-WT (Fig. 4C). Overexpression of miR-3651 had a similar inhibitory effect on the relative luciferase activity of HT29 cells co-transfected with TBX1 3'UTR-WT (Fig. 4D). However, miR-3651 overexpression did not alter the luciferase activity of cells transfected with TBX1 3'UTR-Mut in the two cell lines. Furthermore, RT-qPCR demonstrated that the downregulation of miR-3651 significantly elevated TBX1 mRNA levels in HCT116 and HT29 cells (Fig. 4E). Western blot analysis also indicated the elevation of TBX1 protein expression in HCT116 and HT29 cells (Fig. 4F and G). These data suggested that TBX1 is a target gene of miR-3651 in colorectal cancer cells.
miR-3651 regulates $P I 3 K / A K T$ and MAPK/ERK pathways via targeting TBX1 in colorectal cancer cells. TBX1 has previously been reported to be a regulator of the PI3K/AKT and MAPK/ERK signaling pathways (20). To assess whether TBX1 was associated with the regulation of these signaling pathways via miR-3651, TBX1 expression was silenced via transfection of TBX1 small interfering RNA (siRNA) in HCT116 cells (Fig. 5A and B). The results revealed that TBX1 silencing reversed the miR-3651 downregulation-induced deactivation of the PI3K/AKT and MAPK/ERK signaling pathways (Fig. 5C and D).

miR-3651 promotes colorectal cancer cell proliferation and inhibits cell apoptosis via targeting TBX1. As miR-3651 directly repressed TBX1 expression to activate the PI3K/AKT and MAPK/ERK signaling pathways, it was then hypothesized that TBX1 is essential for miR-3651 function during colorectal cancer cell proliferation. According to the cell proliferation assay results, the silencing of TBX1 reversed the miR-3651 downregulation-induced growth arrest in HCT116 cells (Fig. 6A). Consistent with the results observed in HCT116 cells, TBX1 siRNA also reversed the miR-3651 
A

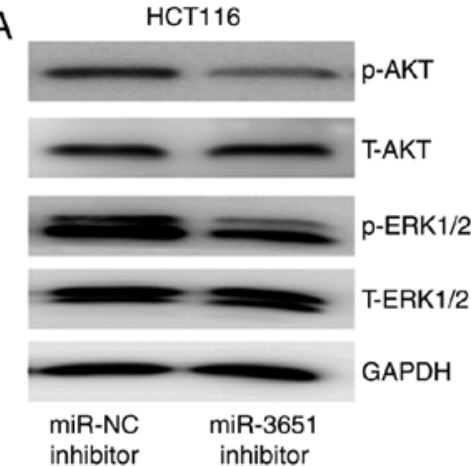

C

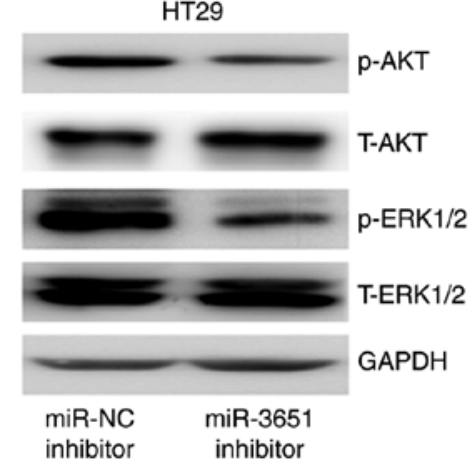

B

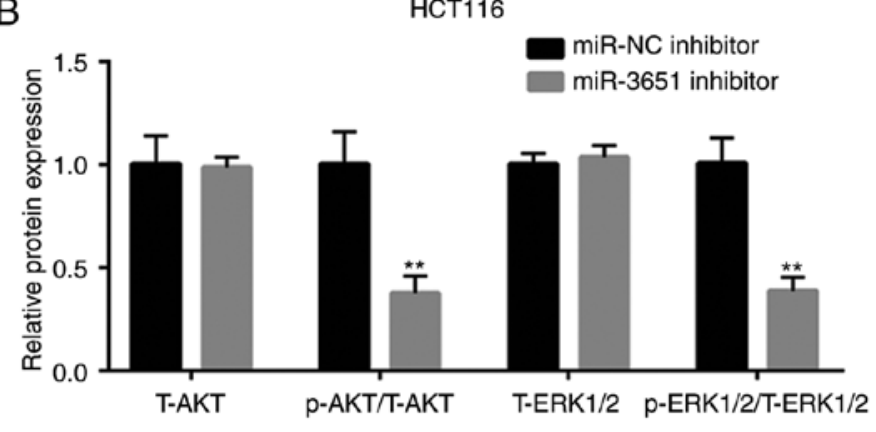

D

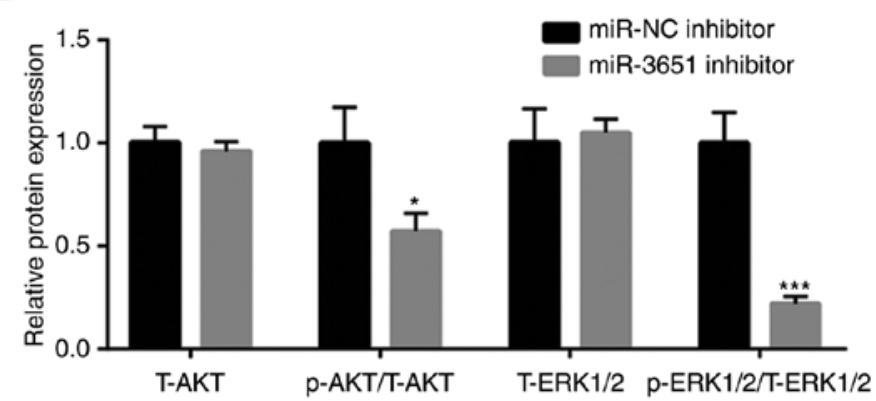

E

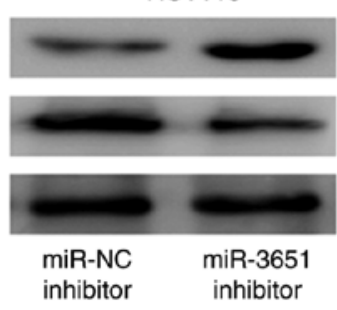

HT29

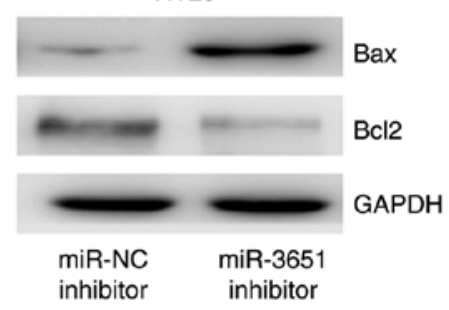

$\mathrm{F}$

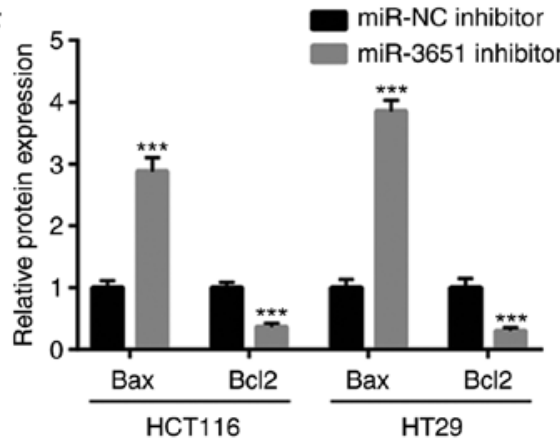

Figure 3. miR-3651 activated the PI3K/AKT and MAPK/ERK signaling pathways in colorectal cancer cells. (A) Western blots and (B) quantified protein expression results revealed that miR-3651 downregulation decreased the ratio of p-AKT/T-AKT and p-ERK1/2/T-ERK1/2 in HCT116 cells. (C) Western blots and (D) quantified protein expression results revealed that miR-3651 downregulation decreased the ratio of p-AKT/T-AKT and p-ERK1/2/T-ERK1/2 in HT29 cells. (E) Western blots and (F) quantified results of Bcl2 and Bax protein expression indicated that miR-3651 downregulation elevated Bax and decreased Bcl2 levels in HCT116 and HT29 cells. ${ }^{*} \mathrm{P}<0.05,{ }^{* *} \mathrm{P}<0.01$ and ${ }^{* * *} \mathrm{P}<0.001$. miR, microRNA; NC, negative control; PI3K, phosphoinositide-3 kinase; AKT, protein kinase B; MAPK, mitogen-activated protein kinase; ERK, extracellular signal-regulated kinase; p-, phosphorylated; T-, total; Bcl2, B-cell lymphoma 2; Bax, Bcl2-associated X protein.

downregulation-induced growth arrest in HT29 cells (Fig. 6B). Furthermore, TBX1 silencing attenuated the elevation of apoptosis that was induced by the miR-3651 inhibitor in HCT116 and HT29 cells (Fig. 6C and D). These results collectively confirmed that miR-3651 regulated colorectal cancer cell proliferation by directly targeting TBX1.

miR-3651 expression is negatively correlated with TBX1 mRNA levels in colorectal tumor tissues. To further investigate the clinical relevance of miR-3651 and TBX1, TBX1 mRNA expression was detected in the 40 pairs of normal and tumor tissues obtained from patients with colorectal cancer. TBX1 was downregulated in $77 \%$ (31/40) of tumors, as compared with the paired normal tissues (Fig. 7A). In addition, Pearson correlation analysis revealed that the miR-3651 expression was negatively correlated with TBX1 mRNA expression in colorectal tumors (Fig. 7B).

\section{Discussion}

Accumulating evidence has indicated that miRNAs serve a role in colorectal cancer progression (27). For instance, microarray analysis of tumors from 12 patients revealed that miR-224 was overexpressed in colorectal adenoma and cancer, and that it regulated KRAS, AKT and ERK signaling activity in colorectal cancer cells (28). Furthermore, in a large cohort of 1,893 carcinoma and normal paired samples, a number of upregulated miRNAs (including miR-204-5p and miR-10a-5p) and downregulated miRNAs (including miR-378a-5p and miR-145-5p) were identified in colorectal cancer (11). Although certain of these have been experimentally verified (29), the role of the majority of differentially expressed miRNAs remains largely undetermined. miR-3651 has been reported to be a prognostic biomarker in esophageal squamous cell, 
A TBX13 UTR-WT 5 -GGGUCCCCGCCCGCCAGUGCCAA-3 hsa-miR-3651 3-GUCACUUAAGAUGGUCACGGUA-5 ||| || TBX1 3 UTR-Mut 5 -GGGUCCCCGCCCGCCAGCGACAA-3
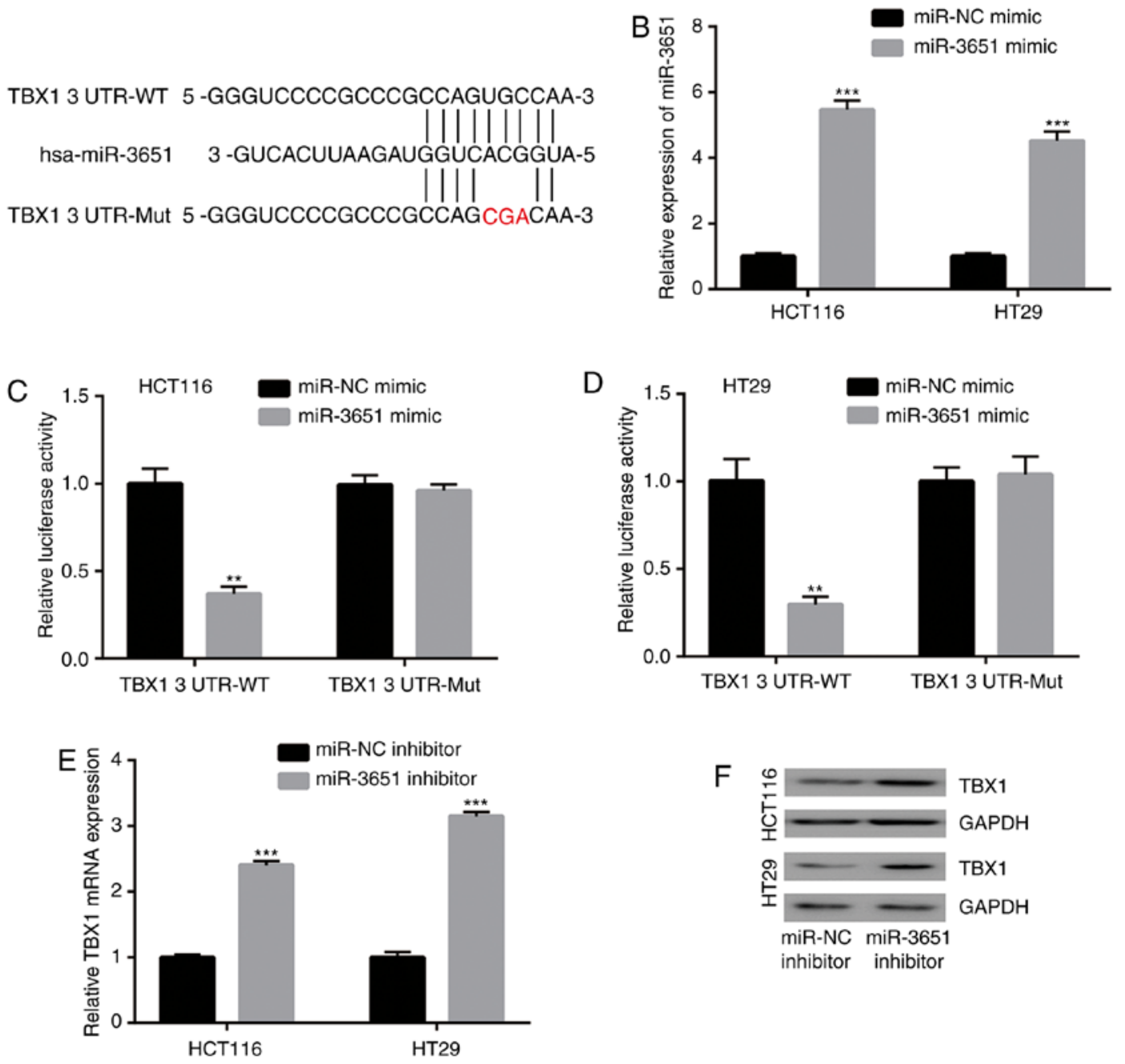

$\mathrm{F}$
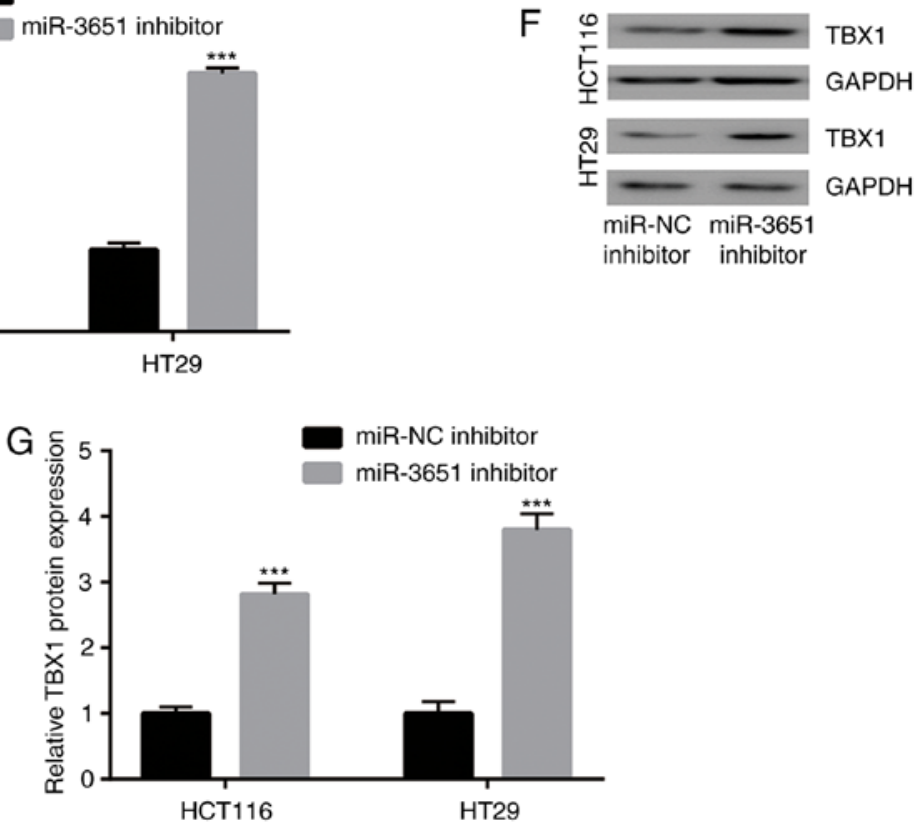

Figure 4. miR-3651 directly repressed TBX1 expression. (A) Bioinformatics analysis indicated that miR-3651 is able to bind to the $3^{\prime} \mathrm{UTR}$ of TBX1 mRNA. (B) Transfection of HCT116 and HT29 cells with miR-3651 mimic successfully increased miR-3651 expression. (C) HCT116 and (D) HT29 cells transfected with TBX1 3'UTR-WT exhibited decreased relative luciferase activity following miR-3651 overexpression, as detected by a dual-luciferase reporter assay. (E) Reverse transcription-quantitative polymerase chain reaction indicated that downregulation of miR-3651 increased TBX1 mRNA expression in HCT116 and HT29 cells. (F) Western blot analysis and (G) quantified protein expression results revealed that downregulation of miR-3651 increased the TBX1 levels in HCT116 and HT29 cells. ${ }^{* *} \mathrm{P}<0.01$ and ${ }^{* * * *} \mathrm{P}<0.001$, vs. miR-NC group. TBX1, T-box transcription factor 1; miR, microRNA; NC, negative control; 3'UTR, 3'-untranslated region; WT, wild-type; Mut, mutant.

oral squamous cell and hepatocellular carcinomas $(13,14,30)$. In another independent study that was based on microarray analysis, miR-3651 was observed to be most significantly upregulated in tumors from 51 patients with colorectal cancer, and these results were confirmed using RT-qPCR (31). In the current study, bioinformatics analysis revealed high expression of miR-3651 in colorectal cancer. Subsequently, the overexpression of miR-3651 in tumor tissues obtained from 40 patients with colorectal cancer was further validated. It was also observed that the downregulation of miR-3651 inhibited the proliferation and induced the apoptosis of colorectal cancer cells. The data gained in the present study suggested a pro-survival and pro-proliferation role of miR-3651 in colorectal cancer.

The MAPK/ERK and PI3K/AKT signaling pathways are well-studied in cancer cells $(32,33)$. In a variety of cancer types, including colorectal cancer, the overactivation of MAPK/ERK and PI3K/AKT pathways has been observed, and indicated 
A

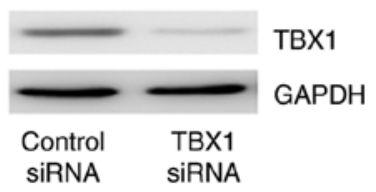

C

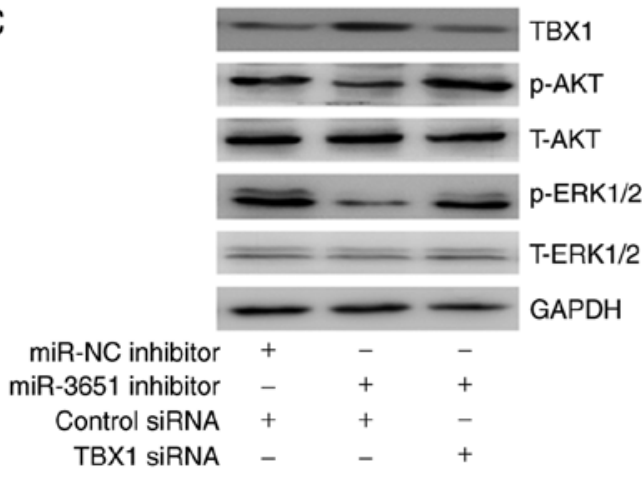

$\mathrm{B}$

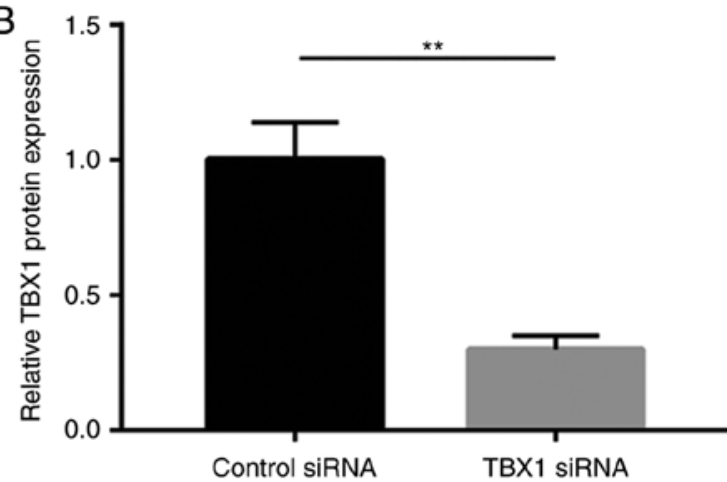

$\mathrm{D}$
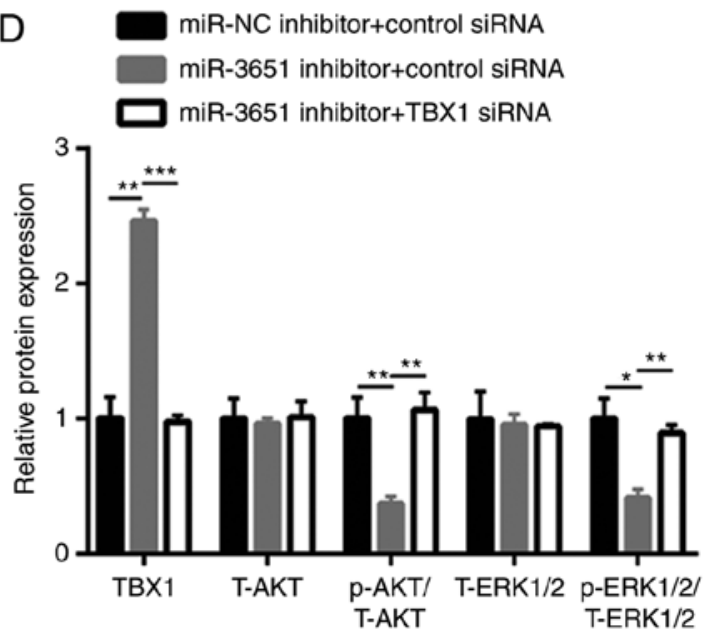

Figure 5. miR-3651 regulated PI3K/AKT and MAPK/ERK pathways via repression of TBX1. (A) Western blots and (B) quantified results, showing that transfection with TBX1 siRNA decreased TBX1 protein expression in HCT116 cells. (C) Western blots and (D) quantified protein expression levels, indicating that miR-3651 downregulation in HCT116 cells increased TBX1 level, and decreased the ratio of p-AKT/T-AKT and p-ERK1/2/T-ERK1/2, which was then reversed by TBX1 silencing. ${ }^{*} \mathrm{P}<0.05,{ }^{* *} \mathrm{P}<0.01$ and ${ }^{* * *} \mathrm{P}<0.001$. miR, microRNA; TBX1, T-box transcription factor 1 ; siRNA, small interfering RNA; NC, negative control; PI3K, phosphoinositide-3 kinase; AKT, protein kinase B; MAPK, mitogen-activated protein kinase; ERK, extracellular signal-regulated kinase; p-, phosphorylated; T-, total.

to be important for cell proliferation and resistance to apoptosis (34-36). In the present study, miR-3651 downregulation was observed to decrease p-ERK1/2 and p-AKT expression levels, demonstrating that miR-3651 mediated the activation of MAPK/ERK and PI3K/AKT pathways in colorectal cancer cells. The inhibition of hyperactivated MAPK/ERK and PI3K/AKT pathways has been demonstrated to lead to cancer cell growth arrest and cell apoptosis $(37,38)$. The current data suggested that miR-3651 may regulate colorectal cancer cell proliferation and apoptosis via the MAPK/ERK and PI3K/AKT pathways.

TBX1 is a transcription factor that mediates key gene expression during development (22), and is a well-documented tumor suppressor in a number of cancer types (20). TBX1 has been revealed to be frequently decreased in papillary thyroid cancer tissues and thyroid cancer cell lines due to the hypermethylation of the gene promoter (20). In thyroid cancer cells, TBX1 regulated cell cycle progression and the expression of apoptosis-associated genes via the MAPK/ERK and PI3K/AKT pathways, while its overexpression inhibited cancer cell proliferation, migration and invasion accompanied with cell cycle arrest and increased cell apoptosis (20). Another study reported that TBX1 was decreased in the tumor tissues of patients with basal cell carcinoma, and that it inhibited cell proliferation and cell cycle progression (21). Furthermore, the overexpression of TBX1 in a mouse spindle cell carcinoma cell line was associated with cell growth inhibition and cell cycle arrest (39). In the current study, TBX1 was predicted to be a target gene of miR-3651 using TargetScan analysis. Similar to its function in thyroid cancer, it was demonstrated that TBX1 also inactivated the MAPK/ERK and PI3K/AKT pathways in colorectal cancer cells. Additionally, miR-3651 regulated the MAPK/ERK and PI3K/AKT pathways via the downregulation of TBX1. TBX1 was previously reported to be a target gene of miR-17-92 cluster, miR-182 and miR-451a in different cell types $(21,40,41)$. In the present study, the results of the dual-luciferase assay also indicated that TBX1 was a target gene of miR-3651 in colorectal cancer cells. Furthermore, miR-3651 exerted its pro-proliferation function by targeting TBX1 in colorectal cancer cells. These results collectively demonstrated the oncogenic potential of miR-3651 in colorectal cancer.

In conclusion, the current study indicated that miR-3651 directly targeted TBX1 to activate the MAPK/ERK and PI3K/AKT pathways, facilitated cell proliferation and inhibited cell apoptosis in colorectal cancer cells. These results provided an insight into the role of miR-3651 in colorectal cancer and the potential application of this miRNA in colorectal cancer therapy. 
A $\rightarrow$ miR-NC inhibitor+control siRNA - miR-3651 inhibitor+control siRNA

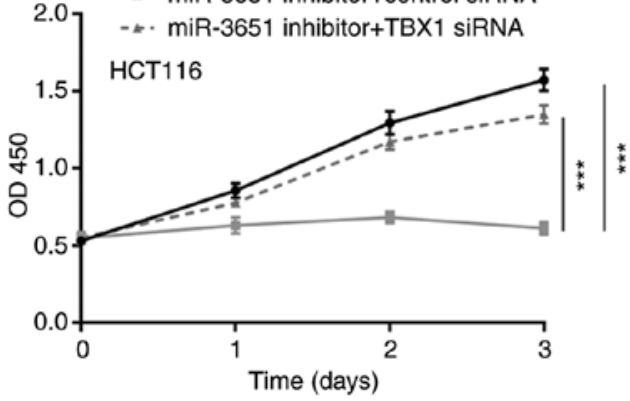

C

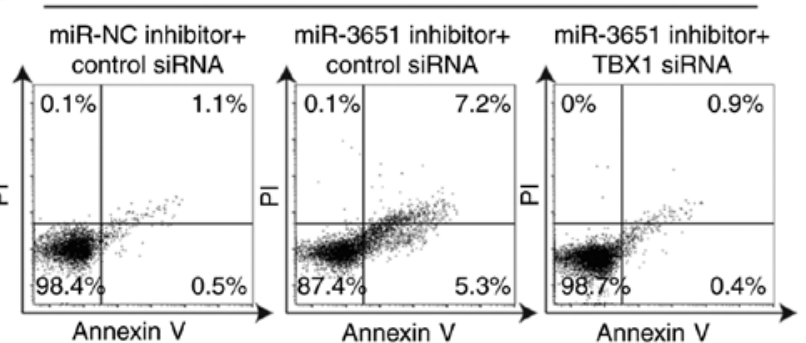

D

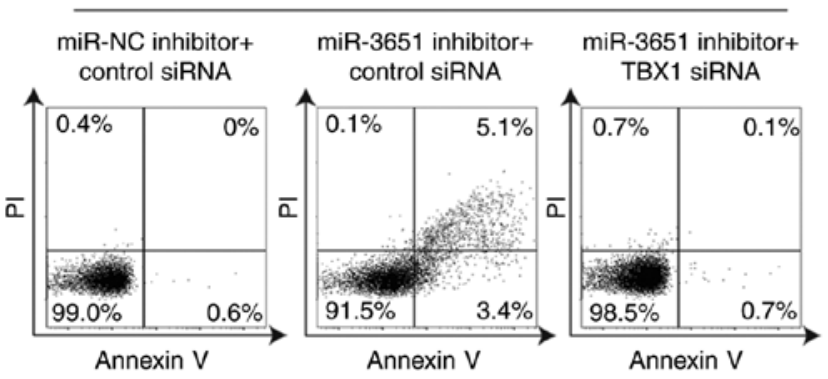

B
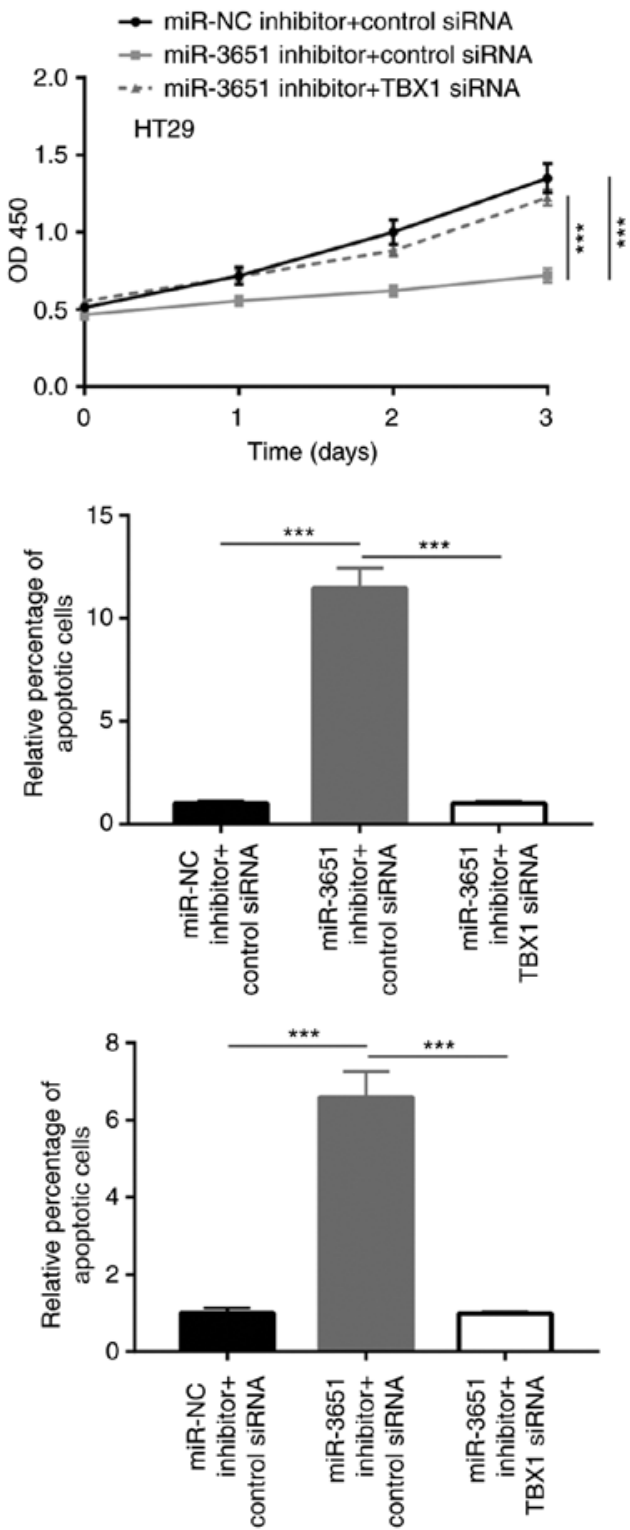

Figure 6. miR-3651 regulated cell proliferation and apoptosis via targeting TBX1 in colorectal cancer cells. Silencing of TBX1 reversed the miR-3651 downregulation-induced growth arrest of (A) HCT116 and (B) HT29 cells, as observed by Cell Counting Kit- 8 assay. Silencing of TBX1 attenuated the miR-3651 downregulation-induced apoptosis of (C) HCT116 and (D) HT29 cells, as observed by flow cytometry analysis. ${ }^{* * *} \mathrm{P}<0.001$. miR, microRNA; TBX1, T-box transcription factor 1; siRNA, small interfering RNA; NC, negative control.
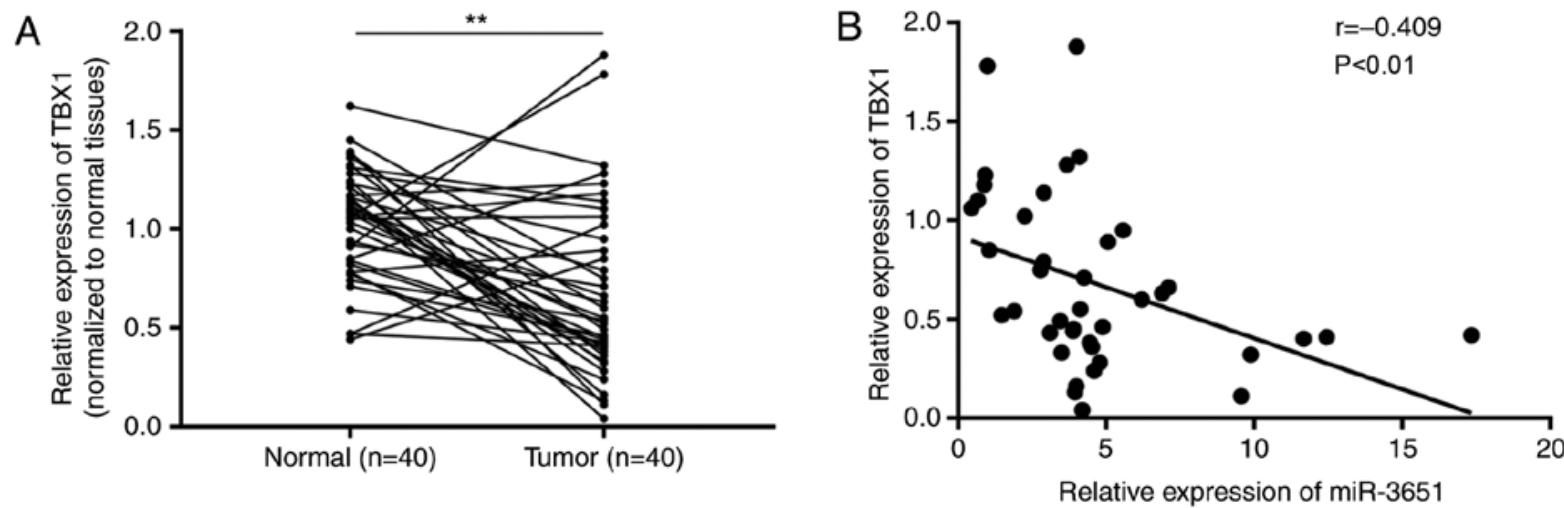

Figure 7. TBX1 mRNA expression was negatively correlated with miR-3651 expression in the tumor tissues of patients with colorectal cancer. (A) Reverse transcription-quantitative polymerase chain reaction analysis of 40 pairs of colorectal cancer and normal tissues indicated significantly decreased TBX1 mRNA expression in tumor tissues. The expression of TBX1 in tumor tissues was normalized to that in paired normal tissues, and the dotted line indicates the relative expression of TBX1 in normal tissues. (B) Pearson correlation analysis revealed that miR-3651 levels were negatively correlated with TBX1 mRNA levels in 40 colorectal tumor specimens. ${ }^{* *} \mathrm{P}<0.01$. TBX1, T-box transcription factor 1; miR, microRNA. 


\section{Acknowledgements}

Not applicable.

\section{Funding}

The present study was approved by the National Natural Science Foundation of China (grant no. 81872323) and the Science and Technology Department of Jilin Province (grant no. 820190303149SF).

\section{Availability of data and materials}

The data are available under special request.

\section{Authors' contributions}

CL, YG and YL performed clinical sample collection. DD designed and supervised the study. DD, YL, CL and YG performed the data acquisition and analysis. YL and DD prepared, edited and revised the manuscript. All authors read and approved the final manuscript.

\section{Ethics approval and consent to participate}

All patients provided written informed consent prior to participation in the study. The Ethic Committee of China-Japan Union Hospital of Jilin University supervised the protocol of the experiments and approved the present study.

\section{Patient consent for publication}

Not applicable.

\section{Competing interests}

The authors declare that they have no competing interests.

\section{References}

1. Bray F, Ferlay J, Soerjomataram I, Siegel RL, Torre LA and Jemal A: Global cancer statistics 2018: GLOBOCAN estimates of incidence and mortality worldwide for 36 cancers in 185 countries. CA Cancer J Clin 68: 394-424, 2018.

2. Hansen RM: Systemic therapy of colorectal cancer. Wis Med J 87: 27-29, 1988.

3. Moriarity A, O'Sullivan J, Kennedy J, Mehigan B and McCormick P: Current targeted therapies in the treatment of advanced colorectal cancer: A review. Ther Adv Med Oncol 8: 276-293, 2016

4. Yates L, Norbury C and Gilbert RC: The long and short of MicroRNA. Cell 153: 516-519, 2013.

5. Ambros V: The functions of animal microRNAs. Nature 431: 350-355, 2004.

6. Rasnic R, Linial N and Linial M: Enhancing identification of cancer types via lowly-expressed microRNAs. Nucleic Acids Res 45: 5048-5060, 2017.

7. Ma Y, Zhang P, Wang F, Zhang H, Yang Y, Shi C, Xia Y, Peng J, Liu W, Yang Z and Qin H: Elevated oncofoetal miR-17-5p expression regulates colorectal cancer progression by repressing its target gene P130. Nat Commun 3: 1291, 2012.

8. Asangani IA, Rasheed SA, Nikolova DA, Leupold JH, Colburn NH, Post S and Allgayer H: MicroRNA-21 (miR-21) post-transcriptionally downregulates tumor suppressor Pdcd 4 and stimulates invasion, intravasation and metastasis in colorectal cancer. Oncogene 27: 2128-2136, 2008.
9. Imaoka H, Toiyama Y, Fujikawa H, Hiro J, Saigusa S, Tanaka K, Inoue Y, Mohri Y, Mori T, Kato T, et al: Circulating microRNA-1290 as a novel diagnostic and prognostic biomarker in human colorectal cancer. Ann Oncol 27: 1879-1886, 2016.

10. Ng L, Wan TM, Man JH, Chow AK, Iyer D, Chen G, Yau TC, Lo OS, Foo DC, Poon JT, et al: Identification of serum miR-139-3p as a non-invasive biomarker for colorectal cancer. Oncotarget 8: 27393-27400, 2017.

11. Slattery ML, Herrick JS, Pellatt DF, Stevens JR, Mullany LE, Wolff E, Hoffman MD, Samowitz WS and Wolff RK: MicroRNA profiles in colorectal carcinomas, adenomas and normal colonic mucosa: Variations in miRNA expression and disease progression. Carcinogenesis 37: 245-261, 2016.

12. Liang G, Li J, Sun B, Li S, Lü L, Wang Y, Chen B and Xiao Z: Deep sequencing reveals complex mechanisms of microRNA deregulation in colorectal cancer. Int J Oncol 45: 603-610, 2014.

13. Wang C, Guan S, Chen X, Liu B, Liu F, Han L, Un Nesa E, Song Q, Bao C, Wang X and Cheng Y: Clinical potential of miR-3651 as a novel prognostic biomarker for esophageal squamous cell cancer. Biochem Biophys Res Commun 465: 30-34, 2015.

14. Ries J, Vairaktaris E, Agaimy A, Kintopp R, Baran C, Neukam FW and Nkenke E: miR-186, miR-3651 and miR-494: Potential biomarkers for oral squamous cell carcinoma extracted from whole blood. Oncol Rep 31: 1429-1436, 2014.

15. Lindsay EA, Vitelli F, Su H, Morishima M, Huynh T, Pramparo T, Jurecic V, Ogunrinu G, Sutherland HF, Scambler PJ, et al: Tbx1 haploinsufficieny in the DiGeorge syndrome region causes aortic arch defects in mice. Nature 410: 97-101, 2001.

16. Chen L, Fulcoli FG, Tang S and Baldini A: Tbx1 regulates proliferation and differentiation of multipotent heart progenitors. Circ Res 105: 842-851, 2009

17. $\mathrm{Xu} \mathrm{H}$, Viola A, Zhang Z, Gerken CP, Lindsay-Illingworth EA and Baldini A: Tbx1 regulates population, proliferation and cell fate determination of otic epithelial cells. Dev Biol 302: 670-682, 2007.

18. Botchkarev VA and Fessing MY: Edar signaling in the control of hair follicle development. J Investig Dermatol Symp Proc 10: 247-251, 2005.

19. Ryan AK, Goodship JA, Wilson DI, Philip N, Levy A, Seidel H, Schuffenhauer S, Oechsler H, Belohradsky B, Prieur M, et al: Spectrum of clinical features associated with interstitial chromosome 22q11 deletions: A European collaborative study. J Med Genet 34: 798-804, 1997.

20. Wang N, Li Y, Wei J, Pu J, Liu R, Yang Q, Guan H, Shi B, Hou P and Ji M: TBX1 functions as a tumor suppressor in thyroid cancer through inhibiting the activities of the PI3K/AKT and MAPK/ERK pathways. Thyroid 29: 378-394, 2019.

21. Sun H and Jiang P: MicroRNA-451a acts as tumor suppressor in cutaneous basal cell carcinoma. Mol Genet Genomic Med 6: 1001-1009, 2018.

22. Fresno Vara JA, Casado E, de Castro J, Cejas P, Belda-Iniesta C and González-Barón M: PI3K/Akt signalling pathway and cancer. Cancer Treat Rev 30: 193-204, 2004.

23. Hari DM, Leung AM, Lee JH, Sim MS, Vuong B, Chiu CG and Bilchik AJ: AJCC cancer staging manual 7th edition criteria for colon cancer: Do the complex modifications. J Am Coll Surg 217: 181-190, 2013.

24. Lu C, Chen X, Wang Q, Xu X and Xu B: TNFa promotes glioblastoma A172 cell mitochondrial apoptosis via augmenting mitochondrial fission and repression of MAPK-ERK-YAP signaling pathways. Onco Targets Ther 11: 7213-7227, 2018.

25. Baldini A, Fulcoli FG and Illingworth E: Tbx1: Transcriptional and developmental functions. Curr Top Dev Biol 122: 223-243, 2017.

26. Livak KJ and Schmittgen TD: Analysis of relative gene expression data using real-time quantitative PCR and the 2(-Delta Delta C(T)) method. Methods 25: 402-408, 2001.

27. Moridikia A, Mirzaei H, Sahebkar A and Salimian J: MicroRNAs: Potential candidates for diagnosis and treatment of colorectal cancer. J Cell Physiol 233: 901-913, 2018.

28. Amankwatia EB, Chakravarty P, Carey FA, Weidlich S, Steele RJ, Munro AJ, Wolf CR and Smith G: MicroRNA-224 is associated with colorectal cancer progression and response to 5-fluorouracil-based chemotherapy by KRAS-dependent and -independent mechanisms. Br J Cancer 112: 1480-1490, 2015.

29. Li S, Wu X, Xu Y, Wu S, Li Z, Chen R, Huang N, Zhu Z and $\mathrm{Xu} X$ : miR-145 suppresses colorectal cancer cell migration and invasion by targeting an ETS-related gene. Oncol Rep 36: 1917-1926, 2016. 
30. Zhu HR, Huang RZ, Yu XN, Shi X, Bilegsaikhan E, Guo HY, Song GQ, Weng SQ, Dong L, Janssen HLA, et al: Microarray expression profiling of microRNAs reveals potential biomarkers for hepatocellular carcinoma. Tohoku J Exp Med 245: 89-98, 2018.

31. Della Vittoria Scarpati G, Calura E, Di Marino M, Romualdi C, Beltrame L, Malapelle U, Troncone G, De Stefano A, Pepe S, De Placido S, et al: Analysis of differential miRNA expression in primary tumor and stroma of colorectal cancer patients. Biomed Res Int 2014: 840921, 2014.

32. Burotto M, Chiou VL, Lee JM and Kohn EC: The MAPK pathway across different malignancies: A new perspective. Cancer 120: 3446-3456, 2014.

33. Martini M, De Santis MC, Braccini L, Gulluni F and Hirsch E: PI3K/AKT signaling pathway and cancer: An updated review. Ann Med 46: 372-383, 2014.

34. de Araujo WM, Robbs BK, Bastos LG, de Souza WF, Vidal FC, Viola JP and Morgado-Diaz JA: PTEN overexpression cooperates with lithium to reduce the malignancy and to increase cell death by apoptosis via PI3K/AKT suppression in colorectal cancer cells. J Cell Biochem 117: 458-469, 2016.

35. Tian XQ, Guo FF, Sun DF, Wang YC, Yang L, Chen SL, Hong J and Fang JY: Downregulation of ZNF278 arrests the cell cycle and decreases the proliferation of colorectal cancer cells via inhibition of the ERK/MAPK pathway. Oncol Rep 38: 3685-3692, 2017.
36. Zhou Q, Chen J, Feng J, Xu Y, Zheng W and Wang J: SOSTDC1 inhibits follicular thyroid cancer cell proliferation, migration, and EMT via suppressing PI3K/Akt and MAPK/Erk signaling pathways. Mol Cell Biochem 435: 87-95, 2017.

37. Vakana E, Pratt S, Blosser W, Dowless M, Simpson N, Yuan XJ, Jaken S, Manro J, Stephens J, Zhang Y, et al: LY3009120, a panRAF inhibitor, has significant anti-tumor activity in BRAF and KRAS mutant preclinical models of colorectal cancer. Oncotarget 8: 9251-9266, 2017.

38. Soo HC, Chung FF, Lim KH, Yap VA, Bradshaw TD, Hii LW, Tan SH, See SJ, Tan YF, Leong CO and Mai CW: Cudraflavone $\mathrm{C}$ induces tumor-specific apoptosis in colorectal cancer cells through inhibition of the phosphoinositide 3-kinase (PI3K)-AKT pathway. PLoS One 12: e0170551, 2017.

39. Trempus CS, Wei SJ, Humble MM, Dang H, Bortner CD, Sifre MI, Kissling GE, Sunman JA, Akiyama SK, Roberts JD, et al: A novel role for the T-box transcription factor Tbx1 as a negative regulator of tumor cell growth in mice. Mol Carcinog 50: 981-991, 2011.

40. Wang J, Bai Y, Li H, Greene SB, Klysik E, Yu W, Schwartz RJ, Williams TJ and Martin JF: MicroRNA-17-92, a direct Ap-2 $\alpha$ transcriptional target, modulates T-box factor activity in orofacial clefting. PLoS Genet 9: e1003785, 2013.

41. Wang XR, Zhang XM, Du J and Jiang H: MicroRNA-182 regulates otocyst-derived cell differentiation and targets T-box1 gene. Hear Res 286: 55-63, 2012. 